\title{
Assessing the ideological homogeneity in entrepreneurial finance research by highly cited publications
}

Quan-Hoang Vuong ${ }^{1}$, Huyen Thanh T. Nguyen (1) ${ }^{1,2}$, Thanh-Hang Pham ${ }^{3}$, Manh-Toan Ho (i) ${ }^{1,2}$ \& Minh-Hoang Nguyen (1) ${ }^{1 \times}$

Entrepreneurs play crucial roles in global sustainable development, but limited financial resources constrain their performance and survival rate. Despite the global presence of entrepreneurship, the literature of entrepreneurial finance is suspected to be Western ideologically homogenous. Thus, this study aims at examining this phenomenon by employing the mindsponge mechanism and bibliometric analyses. 412 highly cited publications extracted from the Web of Science database are analyzed to find Western ideological dominance and low tolerance towards heterogeneity in entrepreneurial finance's core ideologies. These are consistent across author level, institution level, and country levels, revealing strong evidence for the existence of Western ideological homogeneity. We recommend editors, reviewers, and authors diversify research topics proactively and enhance knowledge exchange to avoid shortfalls of ideological homogeneity. Moreover, the synthesis of the mindsponge mechanism and bibliometric analyses are suggested as a possible way to evaluate the state of ideological diversity in other scientific disciplines. 


\section{Introduction}

ntrepreneurship is an important engine that drives the economy and contributes to sustainable development (Fuentelsaz et al., 2015). New ventures create jobs and foster innovation in the economic sector by utilizing internal $R \& D$ activities and capturing external ideas and resources (BeltránMartín et al., 2017). Besides, entrepreneurship also supports poverty reduction in emerging countries without compromising environmental quality (Bruton et al., 2015; Dean and McMullen, 2007; Dhahri and Omri, 2018; Vuong et al., 2019). One of the fundamental factors contributing to start-ups' survival rate and performance is finance (Carpenter and Petersen, 2002; Cosh et al., 2009). There are many financing sources that entrepreneurs can employ to keep their businesses operating, such as venture capital, crowdfunding, private equity, debt, trade credit, angel investor, microfinance, bootstrapping, family/friend loans, etc. (Bruton et al., 2015; Cumming and Groh, 2018).

However, the research about entrepreneurial finance in the last 50 years is seemingly dominant by Western viewpoints. Nguyen et al. (2021) find that the top ten most productive and influential authors, institutions, and countries in entrepreneurial finance research are Western, except for China. Despite being among the top ten most productive countries, China's influence is comparably lower than other Western countries. The two most common research topics in entrepreneurial finance are venture capital and crowdfunding, rooted in the Western history of economic development. For these reasons, Nguyen et al. (2021) suspect that there might be Western ideological homogeneity in the entrepreneurial finance literature. However, this assumption needs further clarification to establish entrepreneurial finance's research agendas to provide practical recommendations for business operations and policymaking. Thus, this study explores whether there is an existence of Western ideological homogeneity in the entrepreneurial finance discipline.

Venture capital's and crowdfunding's vital positions in the entrepreneurial finance literature have been primarily driven by the social-political issues and situations happening along with the histories of the United States (USA) and Europe. Along with Silicon Valley's success, venture capital emerged as a pivotal financing source for start-ups in Western countries during the 1960s (Global Entrepreneurship Institute, n.d.). Its importance within the Western financing system and the literature was later reinforced by the occurrences of major historical events at the end of the 20th century: the collapse of the Soviet Union, the Internet revolution, the Nobel prize of Friedrich Von Hayek, and the promotion of entrepreneurialism (e.g., Thatcherism and Reaganomics), etc. (Senor and Singer, 2011). In the same manner with venture capital, the popularity of crowdfunding was also induced by the rising availability of the Internet and political support. Even though the first successful instance of crowdfunding initially appeared in 1997, only until the Obama administration signed the "CROWDFUND bill" in 2012 for revitalizing small business and entrepreneurship activities after the Great Recession, it gained a pivotal role in entrepreneurial finance (Alper, 2012; Cumming and Groh, 2018).

Studies have found that the national culture (a set of shared values, beliefs, and expected behaviors) greatly influences entrepreneurial activities (Hayton et al., 2002; Turró et al., 2014; Vuong, 2016a, 2016b). Such shared values and beliefs are deeply embedded in the financial system and financing behaviors of entrepreneurs. For example, Musharaka and Mudaraba are two Islamic financing methods often employed by entrepreneurs in Muslim countries (Abou-Gabal et al., 2011), whereas family/ friend financing and bootstrapping are used mainly by Asian entrepreneurs (Guangrong and Enyan, 2011; Pham et al., 2020). Besides culture, entrepreneurial finance is also subject to the political and technological systems (Huynh, 2019; Scott et al., 2020). Entrepreneurs in emerging economies do not just deal with resource constraints but also other obstacles, such as political instability and underdeveloped rule enforcement mechanisms (Scott et al., 2020). The insufficient financial system and lack of technology infrastructure also hinder access to venture capital and crowdfunding in poor regions (Bosma et al., 2020). One of the most frequently proposed financing methods for entrepreneurs in those areas is micro-lending, but it only helps entrepreneurs make ends meet rather than build new businesses (Bruton et al., 2015; Vermeire and Bruton, 2016).

The overemphasis on venture capital and crowdfunding within entrepreneurial finance literature undermines researchers' and policymakers' understanding of other types of financing methods. The dot-com bubble in the past and the COVID-19 pandemic are two prominent examples. While the former was partly a consequence of overreliance on a single financing source-venture capital, the latter teaches us that diversification strategies improve the economy's and businesses' resistance to external shocks (Cowling et al., 2020; Didier et al., 2021; Eggers, 2020). Promoting a more diverse research landscape might help make entrepreneurial finance systems more resilient. Thus, this study, employing the Mindsponge mechanism and bibliometric techniques, aims to assess whether the entrepreneurial finance literature is ideological homogenous or not.

\section{Theoretical background}

Ideology and how to identify it. The definition of ideology is myriad, with the origin of 'ideology' starting more than 200 years ago when first coined by the French philosopher Destutt de Tracy to indicate a new discipline that would study 'ideas': idéologie (Van Dijk, 2006). Since then, a significant number of variations on the definition of ideology have been circulating within the social sciences under different contexts and scenarios (Gerring, 1997). For example, socialists describe ideology as "cultural beliefs that justify particular social arrangements, including patterns of inequality" (Macionis and Gerber, 2010). Meanwhile, political scientists define ideology as "a set of ideas, beliefs, values, and opinions, exhibiting a recurring pattern, that competes deliberately, as well as unintentionally over providing plans of action for public policymaking in an attempt to justify, explain, contest, or change the social and political arrangements and processes of a political community" (Freeden, 2001). The existence of various definitions regarding ideology, indeed, makes the determination of an appropriate definition of ideology for this study's purpose complicated.

In this study, we refer to the definition posed by Van Dijk (2006) because it is widely accepted and defined based on a multidisciplinary framework that combines cognitive, discursive, and social components: "ideology is the foundation of the social representations shared by a social group." To elaborate, the definition is formed based on four characteristics: (1) ideologies are belief systems; (2) the belief systems are socially shared; (3) the shared beliefs need to be fundamental; (4) ideologies are gradually acquired through life or a life period.

An ideology can be distinguished by various means, such as socio-cultural, epistemological, ethical, political, geographical, or religious characteristics of a social group (Vuong et al., 2020). Among those approaches, the classification based on geographical location is one of the most common practices due to its simplicity and straightforwardness. Moreover, based on Van Dijk (2006)'s definition of ideology, we argue that although the ideologies within a specific geographical area might be different politically, epistemologically, and ethnically, they share a fundamental beliefs 
system that has been gradually shaped by economic, environmental, and socio-cultural features in that given area.

In particular, when it comes to Western ideology, neoliberalism is the most recent version, which claims "universal values and modernity, in the form of the liberal global order and globalization" (Gamble, 2009). On the contrary, Asian societies, like China, Vietnam, Korea, and Japan, are featured for Confucian values that promote hierarchically organized order in social relations (Kim, 2009; Vuong et al., 2018). Neoliberalism builds on the early liberal idea of free markets and a laissez-faire economic order (Jones, 2019). These ideas are, indeed, in contrast with the ideologies in Vietnam (e.g., Socialist-Oriented Market Economy) and China (e.g., Socialist Market Economy), in which the market mechanisms are still markedly influenced by socialist economy perspectives.

Finally, after the famous work of Huntington (2000), it is becoming widely accepted that regions with different geographical locations will be significantly divided by a dominating factor, which is culture. Culture is a broad concept that can refer to "the set of norms, practices, and values that characterize minority and majority groups" (Lenard, 2020). Given analogies between culture and ideology, it is plausible to use geographical locations as representations for ideologies.

Ideological homogeneity and how to measure it. For identifying appropriate proxies to measure ideological homogeneity, reviewing its attributes is vital. The issues of homogeneity and heterogeneity have been discussed in social sciences for years, especially political sciences. In sociology, heterogeneity is referred to a society or group that comprises individuals from various ethnicities, cultural backgrounds, sexes, or ages, whereas homogeneity is the absence of heterogeneity (Lawson and Garrod, 2001). Wojcieszak (2010) considers ideological homogeneity as the state of lacking diverse beliefs and principles in a group of like-minded people. In political science, ideological homogeneity or heterogeneity are usually employed for indicating the condition of a political climate in a particular population or environment, such as state, school, workplace, etc. (Atkeson and Taylor, 2019; Kirkland, 2014; Rom, 2019).

Even though the meaning of ideological homogeneity is varying among disciplines, it holds two major characteristics: dominance and low tolerance. On the one hand, the term "dominance" suggests a state in which there is a set of ideas and beliefs regarding how things should happen in a group/society. Therefore, in an ideologically homogenous environment, the community/group/population's viewpoint is driven mainly by the dominant ideology, while other ideologies are suppressed (Atkeson and Taylor, 2019; Journell, 2012). The suppression of different ideologies eventually leads to the second characteristics -low tolerance. Studies have found that political homogeneity is associated negatively with political tolerance (Mutz, 2006; Walsh and Cramer, 2004), whereas a political climate that has diverse political compositions might improve political tolerance (Campbell, 2005). As a result, a low level of tolerance of the community towards various sets of beliefs or values can be another characteristic of ideological homogeneity (Atkeson and Taylor, 2019; Rom, 2019).

Multiple efforts are made to measure the degree of either ideological homogeneity or heterogeneity. In political science, scientists usually employ demographic and opinion proxies to estimate the level of ideological diversity among constituents or population within a specific geographical, legislative, or social boundary (Bond, 1983; Bullock and Brady, 1983; Sullivan, 1973). To elaborate, the higher variance among opinions of respondents, the higher level of ideological heterogeneity, and vice versa
(Levendusky and Pope, 2010). Even though collecting opinion data is expected to provide more advantages than relying on demographic proxies, the method is not applicable in the case of scientific publishing

Therefore, we aim to measure the level of ideological homogeneity by acknowledging the two primary characteristics mentioned above (dominance and low tolerance) and applying them in the context of scientific publishing. In the next section, we would explain how ideological homogeneity can be measured by utilizing the Mindsponge mechanism and bibliometric techniques.

\section{Methods}

To investigate the Western ideological homogeneity in the entrepreneurial finance literature, we focus on evaluating two matters: (i) the dominance of Western ideology among highly cited publications and (ii) the discipline's tolerance of other ideologies other than Western ideology among highly cited publications. The Y-index is employed to assess dominance, while co-authorship analysis is employed to visualize the social structure for evaluating tolerance. Both techniques are conducted across three levels of a publication (author level, institution level, country level) for acquiring different views from the big picture to a finer scale.

Mindsponge mechanism. In scientific publishing, counting the number of publications can help measure an ideology's prevalence in a discipline, just like counting the number of votes in political contexts. However, it is not enough to assess the ideological dominance because a larger quantity does not necessarily represent more considerable influence. For instance, China ranks 4th in scientific production but has a relatively low scientific impact in the entrepreneurial finance discipline (Nguyen et al., 2020). Therefore, identifying the boundary between highly influential publications and popular publications is necessary to assess whether a scientific discipline is ideologically homogenous or not.

We employ the Mindsponge mechanism proposed by Vuong and Napier (2015) for a better explanation of how to assess the ideological homogeneity. We assume that every scientific discipline has a 'nucleus' or a set of ideologies or core values that editors/reviewers/authors use to judge the usefulness of the information or expand the literature (see Fig. 1). This "nucleus" is elusive, but it can be evaluated by analyzing highly cited publications in the field. By nature, highly cited publications are works that pose significant impact and influence over the thinking of other researchers in the respective field (Hui-Zhen and Ho, 2015), which is similar to the functions of the 'mindset' at the individual level (Vuong, 2016a, 2016b; Vuong and Napier, 2015). When a publication is highly cited, the given publication's contained values or ideologies are perceived as crucial for the discipline by many researchers who play as trust evaluators. Eventually, the citation system can be considered the filtering mechanism of a scientific discipline to integrate, synthesize, and incorporate ideologies aligned with the 'nucleus.' The buffer zone surrounding the 'nucleus' is constructed by the scholarly works published by qualified journals. In contrast, the utmost marginal zone contains the cultural and ideological values of a particular setting to which the scientific discipline contributes (here we set as global context).

Based on the mindsponge mechanism, the dominance of an ideology can be measured by counting the number of publications in the nucleus or highly cited publications. The higher prevalence of highly cited publications with a similar ideology, the more dominant the given ideology is within the scientific discipline. 


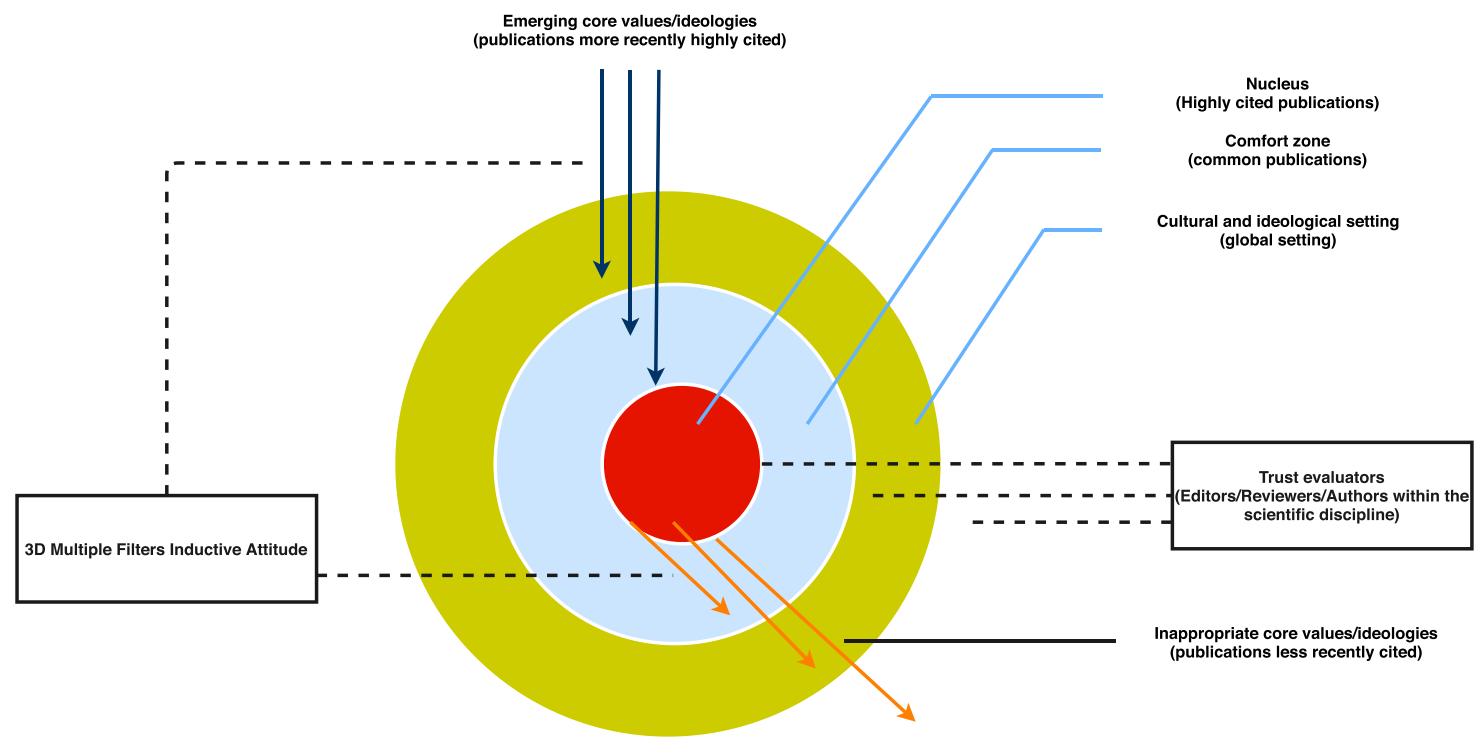

Fig. 1 The mindsponge mechanism in a scientific discipline, adapted from Vuong and Napier (2015).

The ideological dominance alone is not enough to represent the homogeneity, as it lacks an indication of "a group of like-minded people." In an ideologically homogenous group, people tend to "suppress alternative viewpoints, and encourage the selfcensorship of deviant ideas" to avoid conflict (Atkeson and Taylor, 2019). Therefore, a supplementary evaluation indicator of ideological homogeneity is the discipline's tolerance towards heterogeneity. We define tolerance as the degree that the scientific discipline accepts the dominant ideology's coexistence with other different ideologies in the 'nucleus.' In sum, if the proportion of non-dominant ideologies within both the collection of highly cited publications and the boundary of collaboration networks is low or absent, the field can be considered ideological homogenous, and vice versa.

\section{Bibliometrics analysis}

$Y$-index. Full counting or fractional counting are the two most common ways to gauge researchers, institutions, and countries' scientific performance. Full counting gives each of the $\mathrm{N}$ authors full credit of a publication, while fractional counting gives a partial credit of $1 / \mathrm{N}$ to each of $\mathrm{N}$ authors in a publication (Huang et al., 2011). However, both metrics are not suitable in the current analysis, as they fail to address the prominent-authorship position.

Straight counting - attributing credit to the first or corresponding author, was employed instead. The first author and corresponding author are the two most prominent authorship positions in the paper (Mattsson et al., 2011; Riesenberg and Lundberg, 1990). The first author makes the most contribution to the work, including conducting research and writing the manuscript (Riesenberg and Lundberg, 1990). On the other hand, the corresponding author is usually associated with supervising, planning, and coordinating paper writing (Burman, 1982). Both positions have great influences on the manuscript's viewpoints and perceptions. It is further argued that the higher number of authors in a paper has been linked with a higher probability of unethical authorship practices, for example, gift authorship (Chen and Ho, 2015; Ivanović and Ho, 2016). Therefore, using straight counting would help identify the most influential ideology within a co-authored manuscript and avoid counting inappropriate authors that obtain limited contributions to the study (Fu and Ho, 2014).
As a result, Y-index, a straightforward counting method, was selected to assess the ideological dominance. The $\mathrm{Y}$-index is estimated using the number of first-authored (FP) and corresponding (RP) publications. The index has been widely employed in many studies of highly cited papers in multiple fields, such as biomass research, dental research, information, and library science research (Chen and Ho, 2015; Ivanović and Ho, 2016; Yeung and Ho, 2019). The Y-index is defined through two parameters, $j$ and $h$, which are calculated by the following formulas, respectively:

$$
\begin{gathered}
j=\mathrm{FP}+\mathrm{RP} \\
h=\tan ^{-1}\left(\frac{\mathrm{RP}}{\mathrm{FP}}\right)
\end{gathered}
$$

After the $j$ and $h$ value $s$ are obtained, the Y-index can be demonstrated on a two-dimensional polar coordinate with $j \cos h$ being the $x$-axis and $j \sin h$ being the $y$-axis. An author with higher $j$ will hold a more significant role in the field and will be positioned further away from the origin of the polar coordinate $(0,0)$. When the author has equal numbers of corresponding publications and first-authored publications, $h=0.7854$. $h<$ 0.7854 indicates the author to obtain more first-author publications, while $h>0.7854$ indicates the author to obtain more corresponding publications. Notably, $j=$ number of first-author publications when $h=0$, and $j=$ number of corresponding publications when $h=\frac{\pi}{2}$. The calculation can be similarly applied to institution level and country level.

Co-authorship analysis. Co-authorship analysis is a common practice to examine the collaborative activities in a scientific discipline. The analysis documents the interactions among authors to create a co-authorship network or social structure that displays the collaboration patterns of authors and their institutions and countries (Reyes-Gonzalez et al., 2016). The emphasis of co-authorship analysis is not on the authors/institutions/ countries' attributes but the connections among them in the network system (Fonseca et al., 2016). This co-authorship analysis is widely employed to identify key leading and weakly engaged actors in the network and the collaboration tendencies of those actors.

Visually, the network is constructed from a mixture of nodes and edges. Each node in a network represents an author/ 
institution/country, while an edge established between two nodes represents the connection between two given nodes. The size of a node is proportionate to the total frequency of collaborations of the given nodes. In contrast, the size of an edge corresponds to the number of collaborations between two nodes connected by the given edge. The collaboration frequencies among authors/ institutions/countries can be observed through the demonstrations of nodes and edges in a network.

Collaboration has long been considered a means to exchange knowledge, enhance specialization, and integrate complex information, but it requires a consensus among collaborators to achieve the expected outcomes (Sonnenwald, 2007). Therefore, to gain effective collaboration, like-minded people tend to work together; otherwise, there has to be high tolerance of heterogeneity among group members. This pattern has been implied in other studies regarding ideological homogeneity and heterogeneity (Hess and Ganzler, 2007; Journell, 2012). Given the advantages of a collaboration network in illustrating how authors/institutions/countries are connected, we determine to employ co-authorship analysis for evaluating the tolerance of heterogeneity within the "nucleus" of entrepreneurial finance.

Materials. We select the Web of Science (WoS) database as the source of data for this analysis. Governmental agencies and international organizations have used the database, which encompasses a wide range of qualified publications from 1900 to the present, to evaluate scientific performance and the impact of scientists, institutions, and countries (Nguyen et al., 2020).

Entrepreneurial finance is an overlap between entrepreneurship and finance disciplines. Cumming and Johan (2017) assert that entrepreneurial finance literature is so interdisciplinary that it also covers knowledge in disciplines other than entrepreneurship and finance, such as public policy, psychology, sociology, geography, etc. Therefore, we define entrepreneurial finance as studies that cover both the attributes of entrepreneurship and finance. As such, based on prior pieces of literature in entrepreneurship (Aparicio et al., 2019; Vallaster et al., 2019) and finance (Cumming and Groh, 2018; Padilla-Ospina et al., 2018; Xu et al., 2018; Zhang et al., 2019), we select two sets of search keywords, respectively, and then take their intersection using the 'AND' Boolean.

- ("entrepreneur*" OR "startup*“ OR "start-up*" OR "new enterprise*" OR "new firm*")

- ("financ*" OR "debt*“ OR "venture capital*" OR "trade credit*" OR "crowdfund*“ OR "angel invest*“ OR "private

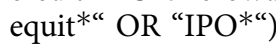

The search was conducted on 2 March 2020 through the field tag "Topic" without restricting publication types or publication period. The only inclusion criterion was that the extracted publications need to be written in English. In total, 10,529 records were retrieved.

To identify highly cited publications, there are currently two predominant methods. One way is to set a specific citation rate or threshold. In contrast, another way is to select a specific number of most cited publications (e.g., top $1 \%$ publications for the number of citations) (X. Zhang et al., 2019). In this study, we employ the former approach to determine highly cited publications; in detail, we set a citation threshold of more than 100 citations. There are two reasons behind this selection. First, limiting highly cited publications to those within the top $1 \%$ publications for the number of citations would reduce the number of publications included in the analysis. Second, the threshold is also applied in many other studies (Barbosa and Schneck, 2015; Fu and Ho, 2016; Zhang et al., 2019). Moreover,

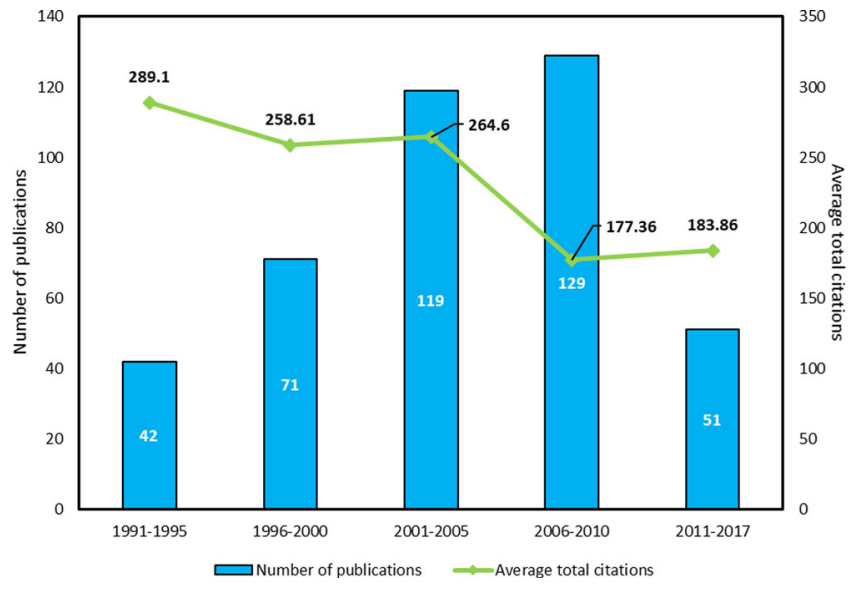

Fig. 2 Number of publications and average total citations.

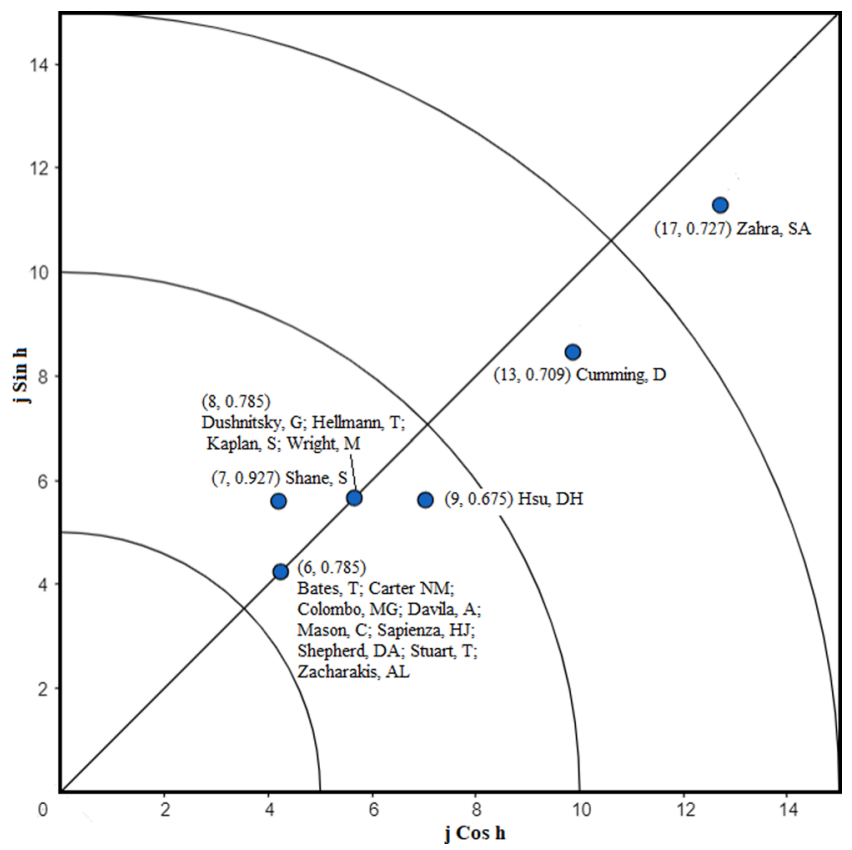

Fig. 3 Distribution of top 17 authors who have $j \geq 5$.

any publications that can receive more than 100 citations are expected to be crucial components of the discipline through quality and visibility dynamics (Aksnes, 2003), so they are all qualified for analysis regardless of publication type. As a result, the publications are not qualified for analysis according to two following exclusion criteria: (1) the publication obtains less than 100 citations, and (2) the publication's authors are anonymous.

Procedure. The analysis in this study is separated into several steps. First, the data is extracted from the WoS database using the aforementioned search keywords and saved as 'csv.' and 'txt.' files. Second, we apply the exclusion criteria to exclude all unqualified publications. Third, we manually disambiguate the authors' names and computationally disambiguate authors' affiliations. For example, 'Cumming D', 'Cumming DJ', and 'Cumming Douglas' refer to the same author. Still, the software will interpret them as different authors if the manual disambiguation process is not conducted. Forth, the first authors' and corresponding authors' names and affiliations are generated in Excel to calculate the Y-index. Lastly, the co-authorship analysis is implemented using the bibliometrix R package (Aria and Cuccurullo, 2017). 


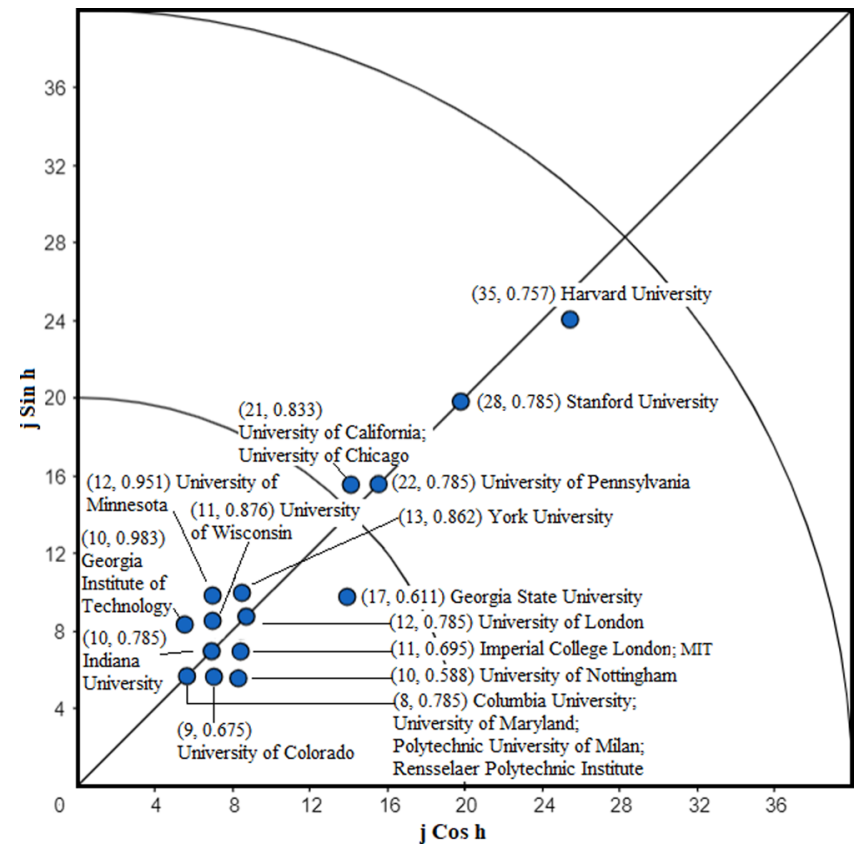

Fig. 4 Distribution of top 20 institutions which have $j \geq 7$.

Limitations of this study are also discussed in the Discussion for transparency (Vuong, 2020).

\section{Result}

Overview. After extracting all publications with total citations (TC) $<100$, we obtain 412 highly cited publications-including 333 articles, 40 reviews, 33 proceeding papers, two editorial materials, two books, and two book chapters. The highly cited publications are written by 729 different authors, of which only 70 are authors of single-authored documents (less than $10 \%$ of total authors). Even though we retrieved data during 1970-2019, highly cited documents only exist during 1991-2017. We split the number of publications and their average citations into five timeframes for better visualization: 1991-1995, 1996-2000, 2001-2005, 2006-2010, and 2011-2017 (see Fig. 2).

\section{Ideological dominance}

Author level. Y-index is an indicator that explores the relevance of an author and his/her contribution characteristics (whether leadership or supervision). Here, we plot the 17 most influential authors (barely more than $2 \%$ of total authors) in entrepreneurial finance. Only authors acquiring a $j$ score larger than five are qualified because decreasing the threshold would lead to the inclusion of many more researchers, which alleviates the presentation clarity. As shown in Fig. 3, the most influential authors lie within the second area of the polar coordinate system. Only Cumming, D and Zahra, SA are located in the third and fourth areas, respectively.

Zahra, SA, with Y-index $(17,0.727)$, is the most influential author in the field of entrepreneurial finance, whereas Cumming, $\mathrm{D}$ comes after with Y-index $(13,0.709)$. Both of them obtain an $h$ score of less than 0.7854 , so they are more likely to take a leading position in a paper. Hsu DH also obtains a similar contribution tendency with Cumming D and Zahra SA. Out of 17 authors, 13 authors have the same number of FP and RP; thus, their $h$ score is equal to 0.7854 . With an $\mathrm{h}$ score higher than 0.7854 , Shane $\mathrm{S}$ is the only author that holds a more significant number of RP than FP. Notably, all of the 17 most influential authors are affiliated with institutions in Europe and North America.
Institution level. Among 371 recorded institutions, only 20 institutions with a $j$ score higher than seven are selected (see Fig. 4). The reason why we set the threshold at seven is similar to the author level Y-index. The presence of institutions in the USA is dominant with 16 universities, while the other three institutions are from the UK (University of London, Imperial College London, and the University of Nottingham). One is from Italy (Polytechnic University of Milan). All four institutions outside the USA are located within the first area of the polar coordinate (from 0 to 20). While University of Nottingham and Imperial College London-Y-index $(10,0.588)$ and Y-index $(11,0.695)$ have reasonably high leadership tendency, University of London and Polytechnic University of Milan hold neutral position between supervision and leadership with Y-index $(12,0.785)$ and Y-index $(8,0.785)$, respectively.

The five most influential institutions in entrepreneurial finance are all from the USA: Harvard University, Stanford University, University of Pennsylvania, University of California, and the University of Chicago. Harvard University is the only institution with an $h$ score of less than 0.7854 , but the difference is negligible $(\mathrm{FP}=18$ and $\mathrm{RP}=17)$. In contrast with Harvard University, the University of California and the University of Chicago-with a Yindex $(21,0.833)$, are more prone to supervision. For other USA institutions in the first area of the polar coordinate, Georgia State University, MIT, and the University of Colorado are more likely to lead research (their $h$ score is less than 0.7854). In contrast, York University, University of Minnesota, University of Wisconsin, and Georgia Institute of Technology are more likely to supervise or conceptualize research (their $h$ score is higher than 0.7854).

With these results, we can see that Western authors and institutions, especially those from the USA, might substantially influence entrepreneurial finance ideology through the scientific output of most impactful publications.

Country level. At the national level, the Y-index presented in Fig. 5 can be firm evidence for the Western ideological homogeneity and a sign of ideological hegemony of the USA in the field of entrepreneurial finance. Figure 4 depicts the Y-indexes of the 15 most influential countries with the $j$ score higher than seven. The USA, UK, and Canada are the three outliers with Y-index (511, 0.795), Y-index (85, 0.750), and Y-index (39, 0.811), respectively. Compared with the UK, the USA's $j$ score completely overweighs with a six-fold greater $j$ score. Nevertheless, the USA is slightly prone to a supervision role in a paper $(\mathrm{FP}=253$ and $\mathrm{RP}=258)$, while the $\mathrm{UK}$ is more prone to the leadership role in a paper $(\mathrm{FP}=44$ and $\mathrm{RP}=41)$.

Looking at the blue box in Fig. 4, we observe a notable trend. Western countries are more prone to supervision roles (such as France, Belgium, and the Netherlands) and neutral positions (such as Italy, Switzerland, Spain, Germany, and Australia) than a leadership role. In contrast, non-Western countries are more likely to hold a leadership role, especially China, with Y-index $(10,0.588)$.

\section{Ideological tolerance}

Author level. At the individual level, the social structure of 729 authors is visualized employing the Louvain clustering algorithm and Kamada-Kawai layout (see Fig. 6). We also set the minimum frequency between two authors as two, which means only the connections with the frequency being higher than one are included in the network.

In total, there are 22 research groups in the "nucleus" of entrepreneurial finance. The size of most research groups is relatively modest, with only two authors. The five authors with 


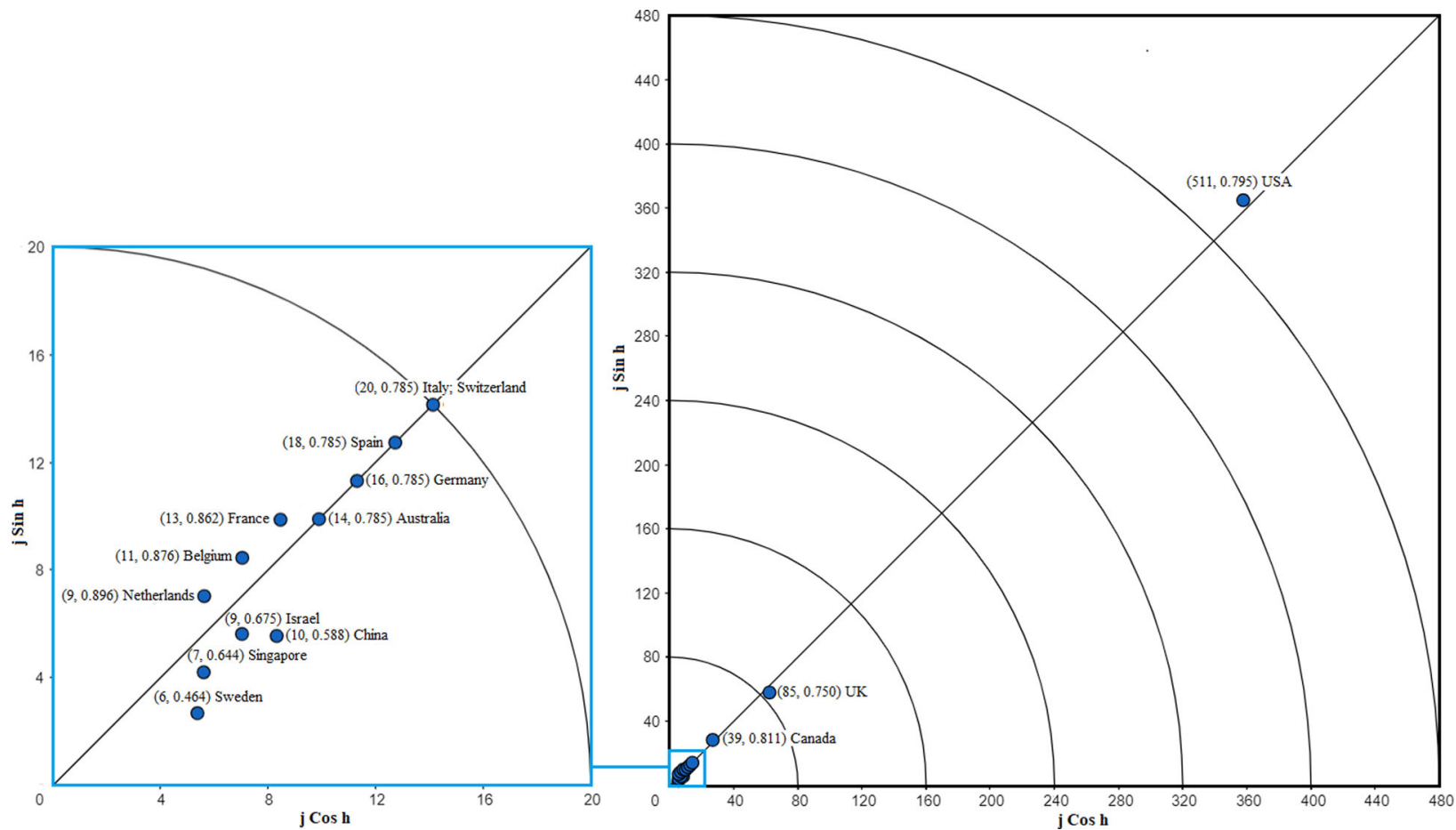

Fig. 5 Distribution of top 15 countries which have $j \geq 7$.

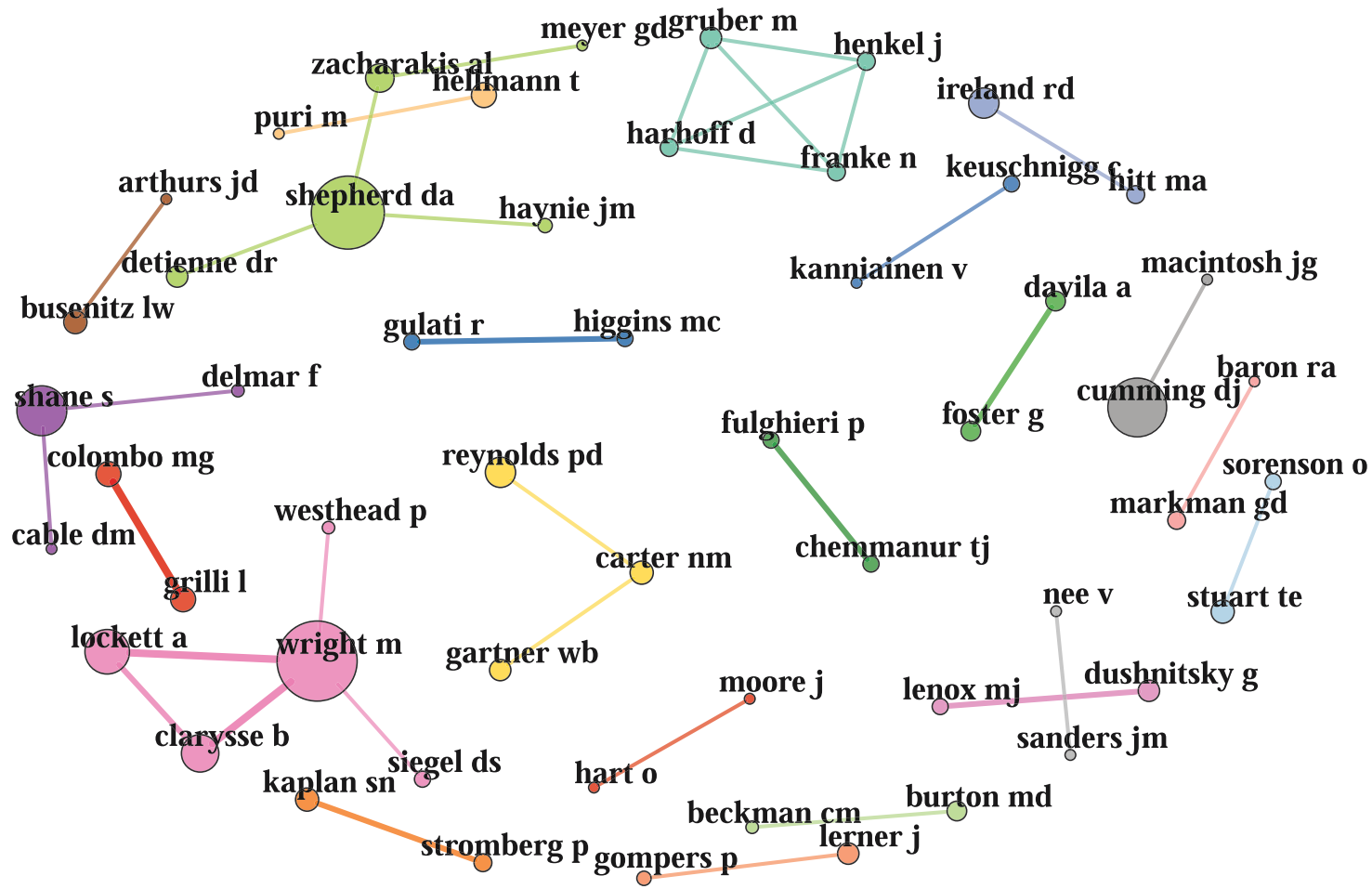

Fig. 6 The social structure at author level.

the highest number of collaboration links are Wright $\mathrm{M}(45$ links), Shepherd DA (41 links), Zahra SA (40 links), Cumming DJ (33 links), and Shane S (28 links). In their research groups, other members are all from Western countries, mostly the USA. A similar collaboration pattern is also observed in other research groups in which members are from Western countries. It is plausible to say the tolerance level of heterogeneity at the author level might be low, or entrepreneurial finance literature might lack knowledge exchange between top Western authors and nonWestern authors.

Institution level. At the institution level, we conduct the coauthorship analysis on 371 institutions using similar settings with the author level. Figure 7 display eight research networks within which member institutions publish at least two highly cited publications together. 27 Western institutions form these research 

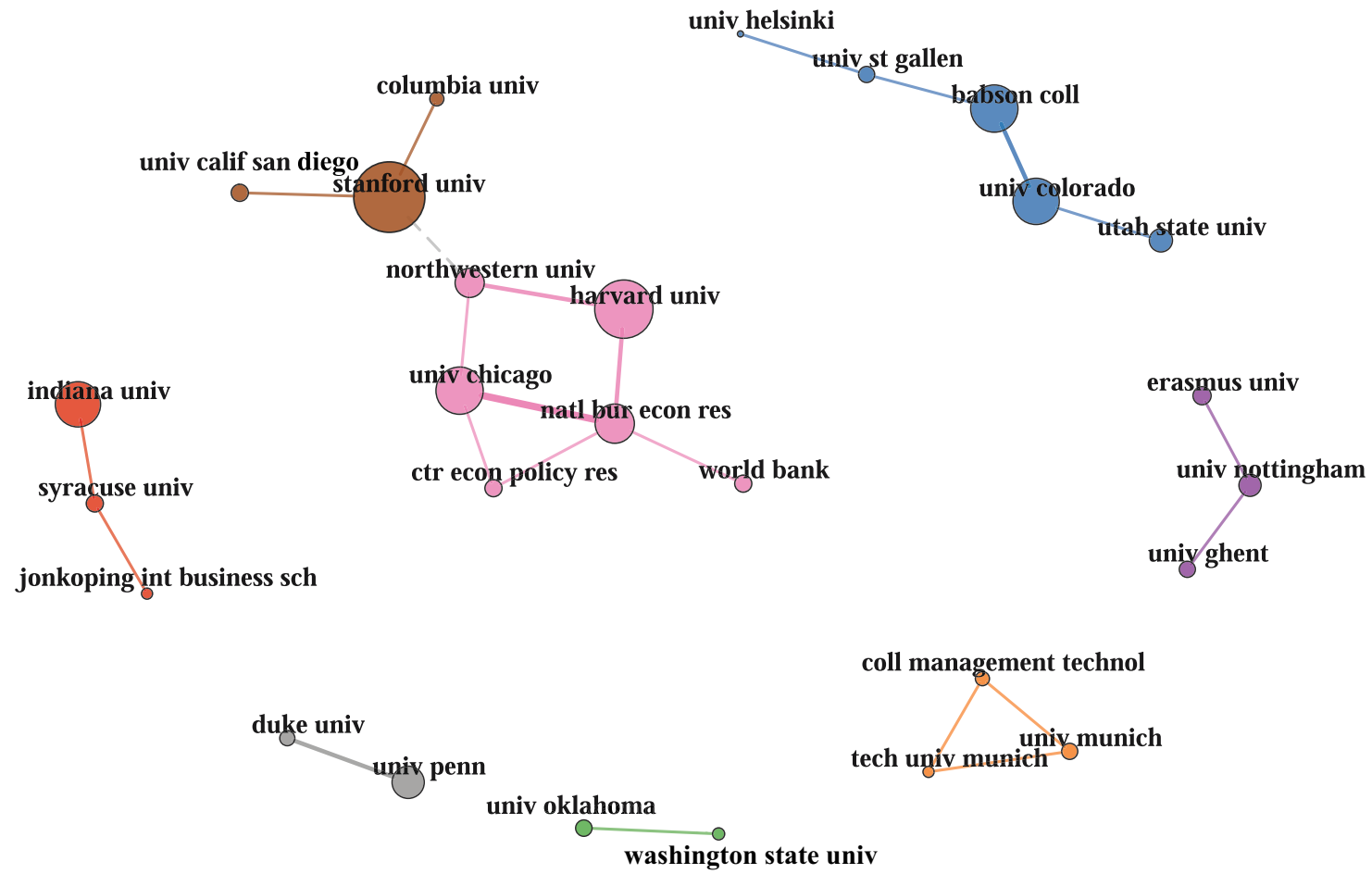

Fig. 7 The social structure at institution level.

networks; not-plotted institutions have either no collaboration with other institutions or collaboration with a frequency of less than two (see Fig. 7). Among 27 institutions, the top ten institutions with the highest number of collaboration links are in the USA; the top five institutions are Stanford University (70 links), Harvard University (58 links), University of Minnesota (48 links), Babson College (47 links), and University of Chicago (47 links). Despite the high degree of collaboration, USA universities frequently collaborate with only institutions in Europe. The only international organization frequently collaborating with the US institution is the World Bank, but that collaborative connection is with a non-educational institution-the National Bureau of Economic Research. Again, the knowledge exchange between Western and non-Western values at the institutional level might also be low.

Country level. Like the author level and institution level, the social structure at the country level is also plotted using the Louvain clustering algorithm and the Kamada-Kawai layout. We also set the minimum frequency between the two countries as two. Out of 32 analyzed countries, 19 countries are included in the collaboration system with three networks (see Fig. 8). In this collaboration system, only China, Korea, and Brazil are non-Western countries, and they belong to the USA's collaboration network. European countries form the other two clusters. In terms of the total collaboration frequency, the US is dominant over other countries with 570 collaboration links, which is more than three times and a half of the second rank-the UK (158 links). There is a signal of knowledge exchange between Western and non-Western countries at the country level in the 'nucleus' of entrepreneurial finance. However, the connection is very scant, given the global prevalence of entrepreneurship.

\section{Discussion}

By calculating the Y-indexes across author level, institution level, and country level, we find the dominance of USA, UK, and Canada's ideologies within the "nucleus" of entrepreneurial finance literature. Specifically, at the author level, all 17 leading authors in terms of Y-index $(j>5)$ are from Western countries. At the institution level, 20 leading universities are Western-based, and $80 \%$ are located in the US. Several non-Western countries appear in the graph at the country level, such as China with Y-index $(10,0.588)$, Israel with Y-index $(9,0.675)$, and Singapore with Y-index $(7,0.644)$. However, their influence is negligible compared to the US with Y-index $(511,0.795)$, the UK with Y-index $(85, .750)$, and Canada with Y-index $(39,0.811)$.

Besides the dominance of Western countries, their low tolerance toward heterogeneous ideologies is also observed. In the social structure within the "nucleus," Western authors, institutions, and countries are prone to collaboration with other Western counterparts. No frequent collaboration connection (collaborating more than one publication) between Western and non-Western authors/institutions is detected, despite the frequent connection between the National Bureau of Economic Research and the World Bank. At the national level, the USA seems to increase its tolerance towards non-Western countries like Brazil, China, and Korea. Still, the overall tolerance of non-Western ideologies is low.

Given the Western countries' dominance and low tolerance of heterogeneity, we support the finding of Nguyen et al. (2020) that the entrepreneurial finance literature might be Western ideologically homogenous. This situation needs to be changed because ideological homogeneity will consequently hinder the development of the discipline. In an ideologically homogenous community, views that challenge common knowledge or ideology are more likely to be rejected or ignored. Although scholars have the freedom to investigate any matter, ideological dominance influences reviewers' and editors' biases who play the roles of "trust evaluators" (see Fig. 1), which subsequently prevents the dissemination of unconventional or unpopular knowledge. In academic publishing, reviewers' and editors' biases due to authors' nationalities are not anything new (Bornmann and Daniel, 2009; Mavrogenis et al., 2020). Besides, authors who have lower academic ranking are also more likely to be the target of coercive 


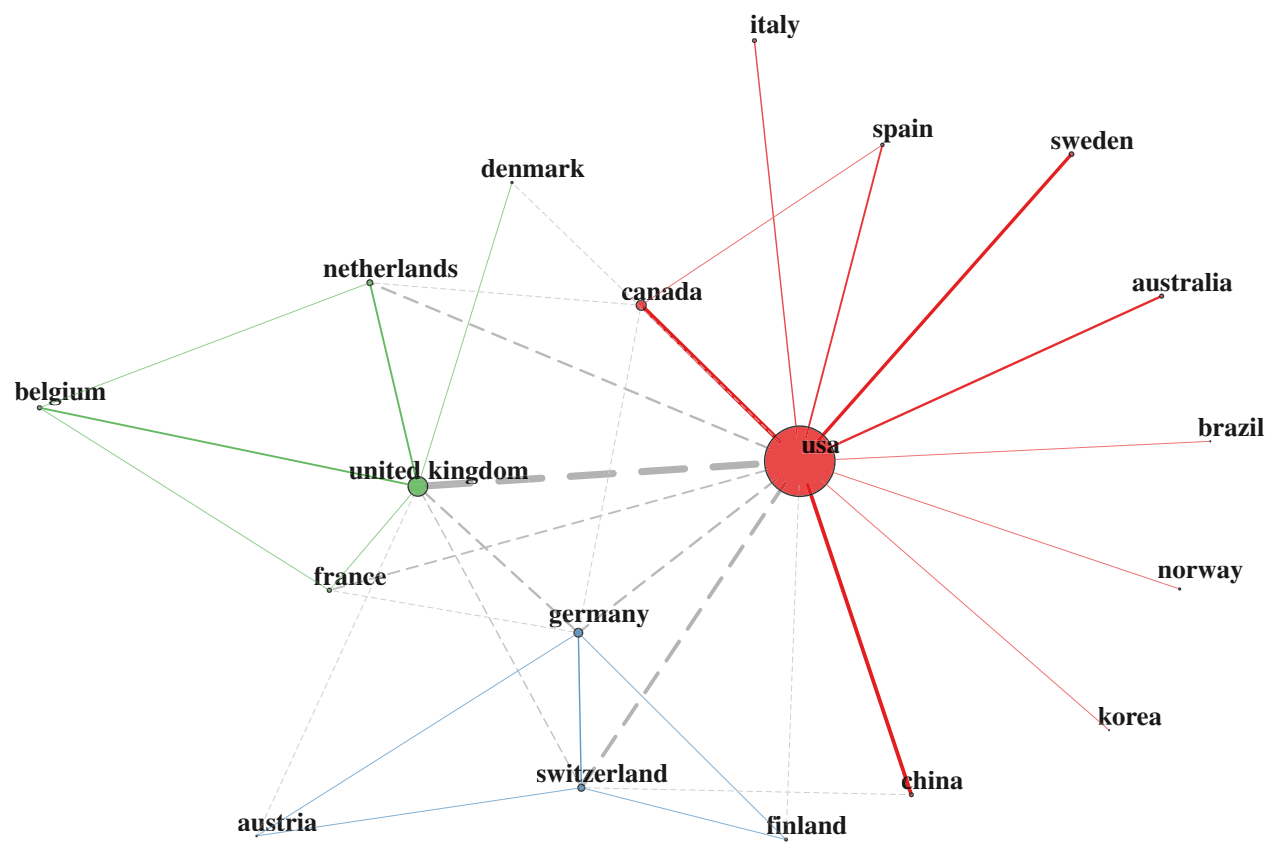

Fig. 8 The social structure at country level.

citation practices, especially in the business discipline (Wilhite and Fong, 2012). Thus, this dominance is more likely to make innovative or new ideas under-evaluated or suppressed (Atkeson and Taylor, 2019; Mahoney, 1977).

Particularly, Second, in a research field with mostly "likeminded' core publications, the level of competitiveness varies between the minority who disseminate non-Western values and the majority who disseminate Western values. On the one hand, viewpoints of the minority tend to receive higher criticism, while the majority enjoy the favorable impact of commonly held perspectives and standards (Campbell, 2019; Journell, 2012; Rom, 2019). Due to this seemingly 'unfriendly' environment, the minority may be less willing to share their opinions. On the other hand, the minority may be encouraged to adjust their viewpoints toward the common core values set by the majority to avoid disagreement (Myers, 1975; Wojcieszak, 2010). Third, ideological homogeneity might undermine science's creditability because scientific uniformity leaves blind spots and narrows the possibility to raise innovative intellectual inquiries (Duarte et al., 2015; Gray, 2019).

Based on the three possible adverse outcomes of ideological homogeneity, we recommend editors, reviewers, and authors to take more proactive attitudes in order to diversify knowledge in entrepreneurial finance. Editors, reviewers, and authors are "trust evaluators" that help filter unqualified values and build up a set of core values through peer-review and citation systems, respectively.

Is the predominance of venture capital and crowdfunding the reason behind Western ideological homogeneity? Or do nonWestern authors obtain a higher rejection rate than Western counterparts because of sharing their local viewpoints? We cannot answer these questions, but we may know that most editors and reviewers in top journals that have high credibility and accessibility are from Western countries. A recent peer-review study indicates that the majority of reviewers are from the USA, UK, and Germany. In contrast, reviewers from developing countries (e.g., China, India, or South Africa) only constitute less than 2\% of the total (Chawla, 2018). As Mahoney's (1977) experiment shows substantial prejudice of reviewers "against manuscripts which reported results contrary to their theoretical perspective," diversifying editorial and reviewer boards in top journals is crucial for providing a fairer filtering process for nonWestern authors. Although there have been several Special Issues about financing sources in non-Western countries (e.g., Islamic finance), they only constitute a small portion of the literature. Therefore, journals should keep promoting ideological heterogeneity through initiating more such Special Issues.

In addition, authors in non-Western countries also need to be proactive in pursuing research topics that are culture-based and advantage-based (Ho et al., 2019). For example, entrepreneurs in Asia are prone to finance from family members, while governmental subsidies are crucial for entrepreneurs in Communist-led countries. Given the tremendous costs and risks to pursue noncommon research topics in emerging countries (Vuong, 2018), researchers in developed countries, especially top authors, should be more open to collaborating with non-Western authors for inducing knowledge exchange and ideological diversity. Although there might be many other reasons that hinder Western top authors to not collaborate with those from emerging countries, we believe that striving to build up some connections to exchange knowledge is still better than none.

Our study is not without limitations. First, social scientists of some countries (e.g., Japan) are prone to publish in the national database due to language barriers, and most of the journals in WoS are published in English. We completely acknowledge that this will favor the assumption on the Western ideological homogeneity in entrepreneurial finance research. Still, given the endeavors to standardize research evaluation systems according to WoS and Scopus systems among developing countries worldwide, we believe the employing data from WoS is one of the optimal alternatives at the moment. Moreover, the problem of ideological homogeneity demonstrated by this study should be centered in the English-language literature, but not all existing research about entrepreneurial finance.

Second, the evidence provided by this study only indicates the ideologically homogeneous core values of entrepreneurial finance but does not consider publications in the "buffer zone" (nonhighly cited publications), so emerging research trends with greater diversity cannot be detected. Third, the mindsponge mechanism of scientific discipline can be used to examine other 
facets of ideologies (e.g., political ideologies, etc.) and the chronological evolution of ideologies. Nevertheless, this study only applies the mechanism on a fixed timeframe and ideological differences following geographical locations. Future studies are recommended to apply the mindsponge mechanism in various disciplines to study the chronological evolution and evaluate other types of ideological diversity.

\section{Conclusion}

Entrepreneurial finance is a rapidly growing field, but the matter of ideological homogeneity is raised for the sake of sustainable development of the field. This research is the first attempt to evaluate the ideological homogeneity in a scientific discipline by employing bibliometric techniques. Based on the Y-index and coauthorship analysis, we find Western ideological dominance and low tolerance of heterogeneity among highly cited papers across three levels (author, institution, and country), strong evidence for the Western ideological homogeneity in entrepreneurial finance. Given various shortfalls of being ideologically homogenous, we recommend editors, reviewers, and authors to take proactive actions for diversifying research topics and enhancing knowledge exchange. Furthermore, the mindsponge mechanism can also be used to judge the chronological evolution and the diversity of core values/ideologies of scientific disciplines other than entrepreneurial finance.

\section{Data availability}

The data that support the findings of this study are available from the Web of Science database of Clarivate Analytics, but restrictions apply to the availability of these data, which were used under license for this study, and so are not publicly available. Data are, however, available from the authors upon reasonable request and with permission of Clarivate Analytics.

Received: 14 December 2020; Accepted: 19 April 2021; Published online: 11 May 2021

\section{References}

Abou-Gabal N, Khwaja A, \& Klinger B (2011) Islamic finance and entrepreneurship: challenges and opportunities ahead. Entrepreneurial Finance Lab Research Initiative Islamic Finance Whitepaper.

Aksnes DW (2003) Characteristics of highly cited papers. Res Eval 12(3):159-170 Alper A (2012) Obama signs bill to boost business startups. Retrieved from https:// www.reuters.com/article/us-usa-jobsact-idUSBRE83414F20120405

Aparicio G, Iturralde T, Maseda A (2019) Conceptual structure and perspectives on Entrepreneurship education research: a bibliometric review. Eur Res Manag Bus Econ 25(3):105-113

Aria M, Cuccurullo C (2017) bibliometrix: An R-tool for comprehensive science mapping analysis. J Informetr 11(4):959-975

Atkeson LR, Taylor AJ (2019) Partisan Affiliation in Political Science: insights from Florida and North Carolina. Polit Sci Polit 52(4):706-710

Barbosa FG, Schneck F (2015) Characteristics of the top-cited papers in species distribution predictive models. Ecol Model313:77-83

Beltrán-Martín I, Bou-Llusar JC, Roca-Puig V, Escrig-Tena AB (2017) The relationship between high performance work systems and employee proactive behaviour: role breadth self-efficacy and flexible role orientation as mediating mechanisms. Hum Resour Manag J 27(3):403-422

Bond JR (1983) The influence of constituency diversity on electoral competition in voting for congress, 1974-1978. Legislative Stud Quart 201-217

Bornmann L, Daniel H-D (2009) Reviewer and editor biases in journal peer review: an investigation of manuscript refereeing at Angewandte Chemie International Edition. Res Eval 18(4):262-272

Bosma N, Hill S, Ionescu-Somers A, Kelley D, Levie J, Tarnawa A (2020) Global entrepreneurship monitor 2019/2020 global report. Retrieved from London: https://www.gemconsortium.org/file/open?fileId $=50443$

Bruton GD, Ahlstrom D, Si S (2015) Entrepreneurship, poverty, and Asia: moving beyond subsistence entrepreneurship. Asia Pacific J Manag 32(1):1-22
Bullock CS, Brady DW (1983) Party, constituency, and roll-call voting in the US Senate. Legisl Stud Quart 29-43

Burman KD (1982) "Hanging from the masthead": reflections on authorship. Ann Int Med 97(4):602-605

Campbell DE (2005) Vote early, vote often: the role of schools in creating civic norms. Educ Next 5(3):62-70

Campbell JE (2019) The trust is gone: what ideological orthodoxy costs. Polit Sci 52 (4):715-719

Carpenter RE, Petersen BC (2002) Is the growth of small firms constrained by internal finance? Rev Econ Statist 84(2):298-309

Chawla DS (2018) Huge peer-review study reveals lack of women and nonWesterners. Nature 561(7722):295-297

Chen H, Ho Y-S (2015) Highly cited articles in biomass research: a bibliometric analysis. Renew Sustain Energy Rev 49:12-20

Cosh A, Cumming D, Hughes A (2009) Outside enterpreneurial capital. Econ J 119 (540):1494-1533

Cowling M, Brown R, Rocha A (2020) Did you save some cash for a rainy COVID19 day? The crisis and SMEs. Int Small Bus J 38(7):593-604

Cumming D, Groh AP (2018) Entrepreneurial finance: unifying themes and future directions. J Corporate Finance 50:538-555

Cumming D, Johan S (2017) The problems with and promise of entrepreneurial finance. Strategic Entrepren J 11(3):357-370

Dean TJ, McMullen JS (2007) Toward a theory of sustainable entrepreneurship: reducing environmental degradation through entrepreneurial action. J Business Ventur 22(1):50-76

Dhahri S, Omri A (2018) Entrepreneurship contribution to the three pillars of sustainable development: what does the evidence really say? World Dev 106:64-77

Didier T, Huneeus F, Larrain M, Schmukler SL (2021) Financing firms in hibernation during the COVID-19 pandemic. J Financial Stability 53:100837

Duarte JL, Crawford JT, Stern C, Haidt J, Jussim L, Tetlock PE (2015) Political diversity will improve social psychological science. Behav Brain Sci 38

e Fonseca BDPF, Sampaio RB, de Araújo Fonseca MV, Zicker F (2016) Coauthorship network analysis in health research: method and potential use. Health Res Policy Syst 14(1):34

Eggers F (2020) Masters of disasters? Challenges and opportunities for SMEs in times of crisis. J Bus Res 116:199-208

Freeden M (2001) Ideology. Political Aspects.

Fu H-Z, Ho Y-S (2014) Top cited articles in adsorption research using Y-index. Res Eval 23(1):12-20

Fu H-Z, Ho Y-S (2016) Highly cited Antarctic articles using Science Citation Index Expanded: a bibliometric analysis. Scientometrics 109(1):337-357

Fuentelsaz L, González C, Maícas JP, Montero J (2015) How Different Formal Institutions Affect Opportunity and Necessity Entrepreneurship. Bus Res Quart 18(4):246-258

Gamble A (2009) The western ideology. Govern Opposit 44(1):1-19. https://doi. org/10.1111/j.1477-7053.2008.01273.x

Gerring J (1997) Ideology: a definitional analysis. Polit Res Quart 50(4):957-994

Global Entrepreneurship Institute (n.d.) History of Silicon Valley. Retrieved from https://siliconvalley.gcase.org/history/

Gray PW (2019) Diagnosis versus ideological diversity. Polit Sci Polit 52 (4):728-731

Guangrong M, Enyan Y (2011) Social networks, informal finance and entrepreneurship. Econ Res J 3:83-94

Hayton JC, George G, Zahra SA (2002) National culture and entrepreneurship: a review of behavioral research. Entrepreneurship Theory Practice 26(4):33-52

Hess D, Ganzler L (2007) Patriotism and ideological diversity in the classroom. In: Westheimer J (ed) Pledging allegiance: the politics of patriotism in America's schools. Teachers College Press, New York, pp. 131-138

Ho L, MT, La VP, Nguyen MH, Vuong TT, Nghiem KC, Tran T, Vuong QH (2019) Health care, medical insurance, and economic destitution: a dataset of 1042 stories. Data 4(2):57

Huang MH, Lin CS, Chen DZ (2011) Counting methods, country rank changes, and counting inflation in the assessment of national research productivity and impact. J Am Soc Inform Sci Technol 62(12):2427-2436

Hui-Zhen F, Ho Y-S (2015) Highly cited Canada articles in Science Citation Index Expanded: a bibliometric analysis. Canadian Social Sci 11(3):50-62

Huntington SP (2000) The clash of civilizations? Foreign Affairs 72(3):22-49

Huynh TLD (2019) Which Google keywords influence entrepreneurs? Empirical evidence from Vietnam. Asia Pacific J Innovat Entrepreneurship 13(2)

Ivanović D, Ho Y-S (2016) Highly cited articles in the Information Science and Library Science category in Social Science Citation Index: a bibliometric analysis. J Librarianship Inform Sci 48(1):36-46

Jones C (2019) Capital, Neoliberalism and Educational Technology. Postdig Sci Educ 1(2):288-292. https://doi.org/10.1007/s42438-019-00042-1

Journell W (2012) Ideological homogeneity, school leadership, and political intolerance in secondary education: a study of three high schools during the 2008 Presidential Election. J School Leadership 22(3):569-599 
Kim T (2009) Confucianism, modernities and knowledge: China, South Korea and Japan. In International Handbook of Comparative Education. Springer, pp. $857-872$

Kirkland JH (2014) Ideological heterogeneity and legislative polarization in the United States. Polit Res Quart 67(3):533-546

Lawson T, Garrod J (2001) Dictionary of sociology. Taylor \& Francis.

Lenard PT (2020) Culture. Retrieved from https://plato.stanford.edu/entries/ culture/

Levendusky MS, Pope JC (2010) Measuring aggregate-level ideological heterogeneity. Legislat Stud Quart 35(2):259-282

Macionis JJ, Gerber LM (2010) Sociology (7th Canadian Edition). Pearson, Canada Mahoney MJ (1977) Publication prejudices: an experimental study of confirmatory bias in the peer review system. Cogn Ther Res 1(2):161-175

Mattsson P, Sundberg CJ, Laget P (2011) Is correspondence reflected in the author position? A bibliometric study of the relation between corresponding author and byline position. Scientometrics 87(1):99-105

Mavrogenis AF, Quaile A, Scarlat MM (2020) The good, the bad and the rude peerreview. Int Orthopaed 44(3):413-415

Mutz DC (2006) Hearing the other side: deliberative versus participatory democracy. Cambridge University Press, Cambridge

Myers DG (1975) Discussion-induced attitude polarization. Hum Relat 28 (8):699-714

Nguyen M-H, Ho M-T, La V-P, Nguyen Q-YT, Ho M-T, Vuong T-T, Vuong Q-H (2020) A Scientometric Study on Depression among University Students in East Asia: Research and System Insufficiencies? Sustainability 12(4):1498

Nguyen MH, Nguyen HTT, Pham, T-H, Nguyen, Q-YT, Vuong, QH (2020) On the 50-Year Research Landscape of Entrepreneurial Finance: A Sign of Western Ideological Homogeneity? Available at SSRN 3612240

Nguyen M-H, Pham T-H, Ho M-T, Nguyen HTT, Vuong Q-H (2021) On the social and conceptual structure of the 50-year research landscape in entrepreneurial finance. SN Bus Econ 1(1):1-29

Padilla-Ospina AM, Medina-Vásquez JE, Rivera-Godoy JA (2018) Financing innovation: a bibliometric analysis of the field. J Bus Finance Librarianship 23 (1):63-102

Pham T-H, Ho M-T, Vuong T-T, Nguyen M-C, Vuong Q-H (2020) Entrepreneurial finance: insights from English language training market in Vietnam. J Risk Financial Manag 13(5):96

Reyes-Gonzalez L, Gonzalez-Brambila CN, Veloso F (2016) Using co-authorship and citation analysis to identify research groups: a new way to assess performance. Scientometrics 108(3):1171-1191

Riesenberg D, Lundberg GD (1990) The order of authorship: who's on first? JAMA 264(14):1857-1857

Rom MC (2019) A liberal polity: ideological homogeneity in Political Science. Polit Sci 52(4):701-705

Scott JM, Sinha P, Gibb, J, Akoorie M (2020) Introduction to the Research Handbook on Entrepreneurship in Emerging Economies. In: Research Handbook on Entrepreneurship in Emerging Economies. Edward Elgar Publishing

Senor D, Singer S (2011) Start-up nation: the story of Israel's economic miracle. Random House Digital, Inc.

Sonnenwald DH (2007) Scientific collaboration. Ann Rev Inform Sci Technol 41 (1):643-681

Sullivan JL (1973) Political correlates of social, economic, and religious diversity in the American states. J Polit 35(1):70-84

Turró A, Urbano D, Peris-Ortiz M (2014) Culture and innovation: the moderating effect of cultural values on corporate entrepreneurship. Technol Forecast Soc Change 88:360-369

Vallaster C, Kraus S, Lindahl JMM, Nielsen A (2019) Ethics and entrepreneurship: a bibliometric study and literature review. J Bus Res 99:226-237

Van Dijk TA (2006) Ideology and discourse analysis. J Polit Ideol 11(2):115-140

Vermeire JA, Bruton GD (2016) Entrepreneurial opportunities and poverty in subSaharan Africa: a review \& agenda for the future. Africa J Manag 2 (3):258-280

Vuong, Q-H (2016a) Global mindset as the integration of emerging socio-cultural values through mindsponge processes: a transition economy perspective. In: Kuada, J (ed) Global Mindsets: Exploration and Perspectives. Routledge, pp. 109-126

Vuong Q-H (2018) The (ir)rational consideration of the cost of science in transition economies. Nat Hum Behav 2(1):5-5. https://doi.org/10.1038/s41562017-0281-4

Vuong Q-H (2020) Reform retractions to make them more transparent. Nature 582:149. https://doi.org/10.1038/d41586-020-01694-x

Vuong Q-H, Bui Q-K, La V-P, Vuong T-T, Nguyen V-HT, Ho M-T, Ho M-T (2018) Cultural additivity: behavioural insights from the interaction of
Confucianism, Buddhism and Taoism in folktales. Pal Commun 4(1):143. https://doi.org/10.1057/s41599-018-0189-2

Vuong Q-H, Ho M-T, Nguyen H-KT, Nguyen M-H (2019) The trilemma of sustainable industrial growth: Evidence from a piloting OECD's Green city. Pal Commun 5(1):1-14

Vuong Q-H, Ho M-T, Nguyen H-KT, Vuong T-T, Tran T, Hoang K-L, La V-P (2020) On how religions could accidentally incite lies and violence: folktales as a cultural transmitter. Pal Commun 6(1):82. https://doi.org/10.1057/ s41599-020-0442-3

Vuong QH (2016b) Impacts of geographical locations and sociocultural traits on the Vietnamese entrepreneurship. SpringerPlus 5(1):1189

Vuong QH, Napier NK (2015) Acculturation and global mindsponge: an emerging market perspective. Int J Intercult Relations 49:354-367

Walsh KC, Cramer KJ (2004) Talking about politics: informal groups and social identity in American life. University of Chicago Press, Chicago

Wilhite AW, Fong EA (2012) Coercive citation in academic publishing. Science 335 (6068):542-543

Wojcieszak M (2010) 'Don't talk to me': effects of ideologically homogeneous online groups and politically dissimilar offline ties on extremism. New Media Soc 12(4):637-655

Xu X, Chen X, Jia F, Brown S, Gong Y, Xu Y (2018) Supply chain finance: a systematic literature review and bibliometric analysis. Int $\mathrm{J}$ Prod Econ 204:160-173

Yeung AWK, Ho YS (2019) Highly cited dental articles and their authors: an evaluation of publication and citation characteristics. J Invest Clin Dentistry 10(4):e12462

Zhang D, Zhang Z, Managi S (2019) A bibliometric analysis on green finance: current status, development, and future directions. Finance Res Lett 29:425-430

Zhang X, Estoque RC, Xie H, Murayama Y, Ranagalage M (2019) Bibliometric analysis of highly cited articles on ecosystem services. PLoS ONE 14(2): e0210707

\section{Acknowledgements}

We would like to thank Mr. Tam-Tri Le (Phenikaa University) for proofreading the manuscript.

\section{Author contributions}

CRediT author statement: conceptualization: Q-HV, M-HN; methodology: M-HN, M$\mathrm{TH}$; formal analysis and investigation: M-HN, M-TH, HTTN; writing-original draft preparation: M-HN, T-HP, HTTN; writing-review and editing: M-HN, T-HP; validation Q-HV; resources: $\mathrm{M}-\mathrm{HN}$; supervision: Q-HV.

\section{Competing interests}

The authors declare no competing interests.

\section{Additional information}

Correspondence and requests for materials should be addressed to M.-H.N

Reprints and permission information is available at http://www.nature.com/reprints

Publisher's note Springer Nature remains neutral with regard to jurisdictional claims in published maps and institutional affiliations.

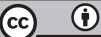

Open Access This article is licensed under a Creative Commons Attribution 4.0 International License, which permits use, sharing, adaptation, distribution and reproduction in any medium or format, as long as you give appropriate credit to the original author(s) and the source, provide a link to the Creative Commons license, and indicate if changes were made. The images or other third party material in this article are included in the article's Creative Commons license, unles indicated otherwise in a credit line to the material. If material is not included in the article's Creative Commons license and your intended use is not permitted by statutory regulation or exceeds the permitted use, you will need to obtain permission directly from the copyright holder. To view a copy of this license, visit http://creativecommons.org/ licenses/by/4.0/

(c) The Author(s) 2021 